\title{
Variabilidade Genética em Populações Naturais de Bromus auleticus Trin. ex Nees (Poaceae) com Base em Isoenzimas e Marcadores RAPD ${ }^{1}$
}

\author{
Fabiana Yuriko Yanaka², Miguel Dall'Agnol3 ${ }^{3}$, Maria Teresa Schifino-Wittmann³, Paula Menna \\ Barreto Dias ${ }^{2}$, Klecius Ellera Gomes ${ }^{4}$
}

\begin{abstract}
RESUMO - Bromus auleticus é uma espécie perene, nativa do estado do Rio Grande do Sul, que tem demonstrado adaptabilidade, potencial para produção de forragem de qualidade e alta diversidade morfológica. Neste trabalho, foram analisados padrões de bandas de sistemas enzimáticos e de marcadores RAPD, com o objetivo de determinar a variabilidade genética em 16 acessos de Bromus auleticus do Rio Grande do Sul. A variabilidade foi avaliada pelo índice de similaridade de Jaccard, utilizando-se o método UPGMA nas análises de agrupamento. Os índices de similaridade variaram de 0,0 a 0,50 com base em isoenzimas e de 0,15 a 0,71 com base em marcadores RAPD. Os dados foram eficientes para a formação de grupos, indicando a variabilidade genética dos acessos analisados. Entretanto, houve baixa relação entre os agrupamentos e os locais de coleta. A variabilidade genética dos acessos é importante sob o ponto de vista do melhoramento genético, permitindo a seleção futura dos genótipos a partir de seus respectivos desempenhos. A utilização simultânea de isoenzimas e RAPD foi eficiente na caracterização da diversidade genética dos acessos analisados.
\end{abstract}

Palavras-chave: Bromus auleticus, isoenzimas, RAPD, variabilidade genética, forrageiras nativas

\section{Genetic Variability in Natural Populations of Bromus auleticus Trin. ex Nees (Poaceae) Using Isozymes and RAPD Markers}

\begin{abstract}
Bromus auleticus is a perennial, native species of the state of Rio Grande do Sul, which has demonstrated adaptability, potential yield of good quality forage as well as high morphological diversity. This work has analyzed band patterns from enzymatic systems and RAPD markers, with the objective to access the genetic variability in 16 accessions of Bromus auleticus from Rio Grande do Sul. The variability was evaluated using Jaccard similarity index. The method of grouping based on the average (UPGMA) was used in cluster analyses. The similarity index ranged from 0.0 to 0.50 using isozumes and from 0.15 to 0.71 using RAPD markers. The data have been efficient for the formation of different groups, indicating the genetic variability of the accession analyzed. However, these groupings have little relationship with the respective collecting places. The genetic variability of the accessions is important to the genetic improvement, allowing future genotype selection based on their respective performances. The simultaneous utilization of isozymes and RAPD was efficient in characterizing the genetic diversity of the accessions evaluated.
\end{abstract}

Key Words: Bromus auleticus, isozymes, RAPD, genetic variability, native forages

\section{Introdução}

O gênero Bromus compreende mais de 100 espécies anuais e perenes de gramíneas tipicamente de estação fria distribuídas pelo mundo e que variam bastante quanto ao uso e à adaptação (Mabberley, 1997). O gênero inclui algumas espécies forrageiras importantes como as perenes $B$. inermis, $B$. anomalus, B. pumpellianus e B. catharticus, e as anuais B. mollis e $B$. rigidus, entre outras (Carlson \& Newell, 1985). No Rio Grande do Sul, ocorrem três espécies nativas (B. auleticus, B. brachyanthera e $B$. catharticus) e duas exóticas (B. commutatus e B. mollis) (Longhi, 1977). Entre as espécies nativas, a alógama (Rivas,
2001) B. auleticus, popularmente chamada de "Cevadilha Vacariana” ou "Cevadilha” (Araújo, 1971), ocorre comumente em regiões onde a produção animal depende fortemente das pastagens naturais. A maioria das espécies deste ecossistema são de crescimento estival e, conseqüentemente, há escassez de forragem nos meses de inverno, o que se reflete em menor produção animal. A identificação, caracterização, avaliação e utilização posterior das espécies nativas de crescimento hibernal, como $B$. auleticus, são prioridades na pesquisa agronômica da região. Todas as populações do Rio Grande do Sul analisadas até o momento são hexaplóides, com 2n= 42 cromossomos (Martinello \& Schifino-Wittmann, 2003).

\footnotetext{
1 Parte da dissertação de Mestrado apresentada ao PPG em Zootecnia, UFRGS.

2 Mestre em Zootecnia, UFRGS.

3 Professor do Departamento de Plantas Forrageiras e Agrometeorologia, Faculdade de Agronomia, UFRGS, Porto Alegre, RS. Bolsista do CNPq. E.mail: migueld@ufrgs.br

4 Pesquisador da Embrapa Pecuária Sul, Bagé, RS. Endereço atual: Embrapa Superintende.
} 
A caracterização de germoplasma e a estimativa da variabilidade genética são essenciais em qualquer projeto que envolva recursos genéticos. A morfologia tem sido muito utilizada, mas os marcadores bioquímicos e especialmente os moleculares fornecem uma abordagem mais próxima do genoma. As isoenzimas, que refletem os produtos gênicos diretos, são meios eficientes para se estimar a variabilidade (Soltis \& Soltis, 1989) e têm sido amplamente utilizadas em estudos taxonômicos, genéticos e evolutivos. A natureza co-dominante das bandas e seus custos relativamente baixos da técnica tornam a análise de isoenzimas uma técnica atraente e útil na pesquisa. Além disso, são especialmente úteis para a comparação de diversos táxons, acessos ou indivíduos (Klaas, 1998). Os marcadores moleculares de DNA são recursos muito eficientes para a determinação da variabilidade genética, por analisarem diretamente $o$ material genético. Atualmente, quase todos os trabalhos de caracterização de germoplasma incluem um ou mais tipos de marcadores moleculares e, entre os marcadores de DNA baseados em PCR (Polimerase Chain Reaction), os RAPD (Random Amplified Polymorphic $D N A$ ) têm sido os mais utilizados.

Objetivou-se neste trabalho a caracterização de acessos de cevadilha por meio de análises isoenzimáticas e de RAPD, a fim de se estabelecerem as relações genéticas entre eles e utilizar essas informações em programas de melhoramento genético desta espécie.

\section{Material e Métodos}

Sementes de 16 populações naturais de B. auleticus foram coletadas em diversos locais do Rio Grande do Sul (Tabela 1). Cada amostra foi considerada um acesso. Os termos acessos e população serão utilizados como sinônimos ao longo do texto.

As sementes foram germinadas em placas de petri com papel-filtro umedecido. Plântulas com alturas entre 2 e $3 \mathrm{~cm}$ foram transferidas para vasos plásticos com capacidade de $1 \mathrm{~kg}$ e mantidas em casa de vegetação. Dez indivíduos por acesso foram analisados para RAPD e cinco para isoenzimas. Dos 16 acessos, nove foram analisados por meio de marcadores isoenzimáticos, 12 por meio marcadores RAPD e seis pelos dois tipos de marcadores.

Foi realizada uma análise preliminar de dez sistemas enzimáticos (álcool-desidrogenase, enzima málica, $\beta$-esterase, fosfo-glico-isomerase, glicose-desidrogenase, isocitrato-desidrogenase, peroxidase e superóxidodismutase), sendo que os sistemas $\beta$-esterase e peroxidase foram selecionados, em razão do polimorfismo de bandas, da qualidade e definição de bandas e da repetibilidade. Foram utilizadas folhas jovens frescas e a extração foi feita conforme técnicas descritas por Rivas (2001). Os procedimentos de eletroforese e coloração dos géis atenderam os protocolos de González \& Schifino-Wittmann (1996) e

Tabela 1 - Acessos de Bromus auleticus analisados

Table 1 - Analyzed accessions of Bromus auleticus

\begin{tabular}{|c|c|c|c|c|c|}
\hline $\begin{array}{l}\text { Número } \\
\text { Number }\end{array}$ & $\begin{array}{l}\text { Código } \\
\text { Code }\end{array}$ & $\begin{array}{l}\text { Local de coleta } \\
\text { Place of collection }\end{array}$ & $\begin{array}{l}\text { Latitude } \\
\text { Latitude }\end{array}$ & $\begin{array}{l}\text { Longitude } \\
\text { Longitude }\end{array}$ & $\begin{array}{l}\text { Altitude } \\
\text { Altitude }\end{array}$ \\
\hline 01 & GoDu $87^{a}$ & Bagé & $31^{\circ} 11^{\prime} \mathrm{S}$ & $53^{\circ} 50^{\prime} \mathrm{W}$ & 300 \\
\hline 03 & OvGoMgGu $64^{\mathrm{a}}$ & Livramento & $30^{\circ} 35^{\prime} \mathrm{S}$ & $56^{\circ} 02^{\prime} \mathrm{W}$ & 220 \\
\hline 04 & OvGoMgGu $66^{\mathrm{a}}$ & Livramento & $30^{\circ} 39^{\prime} \mathrm{S}$ & $56^{\circ} 05^{\prime} \mathrm{W}$ & 220 \\
\hline 05 & OvGoMgGu $69^{\mathrm{a}}$ & Livramento & $30^{\circ} 34^{\prime} \mathrm{S}$ & $56^{\circ} 04^{\prime} \mathrm{W}$ & 200 \\
\hline 08 & GoRg $121^{\mathrm{a}}$ & Júlio de Castilhos & $29^{\circ} 19^{\prime} \mathrm{S}$ & $53^{\circ} 40^{\prime} \mathrm{W}$ & 490 \\
\hline 09 & GoOv $59^{a}$ & Pinheiro Machado & $31^{\circ} 33^{\prime} \mathrm{S}$ & $53^{\circ} 25^{\prime} \mathrm{W}$ & 415 \\
\hline 10 & $\mathrm{GoOv} 62^{\mathrm{a}}$ & Dom Pedrito & $31^{\circ} 04^{\prime} \mathrm{S}$ & $54^{\circ} 30^{\prime} \mathrm{W}$ & 180 \\
\hline 11 & OvRgVj $44^{\mathrm{a}}$ & Pinheiro Machado & $31^{\circ} 31^{\prime} \mathrm{S}$ & $53^{\circ} 31^{\prime} \mathrm{W}$ & 420 \\
\hline 12 & GoLe $110^{\mathrm{a}}$ & Livramento & $30^{\circ} 33^{\prime} \mathrm{S}$ & $56^{\circ} 07^{\prime} \mathrm{W}$ & 196 \\
\hline 13 & OvGoGu $107^{\mathrm{a}}$ & Cruz Alta & $28^{\circ} 37^{\prime} \mathrm{S}$ & $53^{\circ} 25^{\prime} \mathrm{W}$ & 440 \\
\hline
\end{tabular}

a acessos do banco de germoplasma da EMBRAPA-CPPSul (accessions from the germplasm bank of EMBRAPA-CPPSul). n.d.- não disponível (not available). 
Tabela 2 - Iniciadores utilizados para obtenção dos marcadores RAPD e respectiva seqüência de nucleotídeos

Table 2 - Primers used to obtain RAPD markers and respective nucleotide sequences

\begin{tabular}{|c|c|}
\hline $\begin{array}{l}\text { Iniciador } \\
\text { Primer }\end{array}$ & $\begin{array}{l}\text { Seqüência } \\
\text { Sequence }\end{array}$ \\
\hline OPC-01 & $5^{\prime}$ - TTC GAG CCA G - 3' \\
\hline OPC-02 & $5^{\prime}-$ GTG AGG CGT C - 3' \\
\hline OPC-03 & $5^{\prime}-$ GGG GGT CTT T - 3' \\
\hline OPC-04 & $5^{\prime}-\mathrm{CCG}$ CAT CTA C $-3{ }^{\prime}$ \\
\hline OPC-05 & $5^{\prime}-\mathrm{GAT}$ GAC CGC C - 3' \\
\hline OPC-06 & $5^{\prime}-$ GAA CGG ACT C -3 ' \\
\hline OPC-07 & $5^{\prime}-\mathrm{GTCCCG}$ ACG A - 3' \\
\hline OPC-08 & $5^{\prime}-\mathrm{TGG}$ ACC GGT G - 3' \\
\hline OPC-09 & $5^{\prime}-\mathrm{CTC}$ ACC GTC C $-3^{\prime}$ \\
\hline
\end{tabular}

Lange \& Schifino-Wittmann (2000), com adaptações. Para evitar possíveis distorções no cálculo das taxas de migração ( $\mathrm{rm}$ = distância percorrida pela banda/ distância da linha de frente) em diferentes géis (Alfenas et al., 1991), foi feita uma correção com base em uma banda controle, como descrito por González \& SchifinoWittmann(1996) e Lange \& Schifino-Wittmann(2000).

Para análise de RAPD, o DNA foi extraído de folhas jovens frescas, de acordo com Thomson \& Henry (1995), com algumas modificações. O tecido foi macerado em nitrogênio líquido, misturado com $300 \mu \mathrm{L}$ do tampão de extração (Tris $\mathrm{HCl} 0,1 \mathrm{M}, \mathrm{KCl}$ $0,86 \mathrm{M}$ e EDTA $0,04 \mathrm{M}$ ) e incubado a $95^{\circ} \mathrm{C}$ por 10 minutos. Após a incubação, o extrato foi centrifugado a $13.000 \mathrm{rpm}$. O sobrenadante foi transferido para um novo tubo e o DNA precipitado pela adição de $600 \mu \mathrm{L}$ de etanol $95 \%$ e $90 \mu \mathrm{L}$ de acetato de sódio $3 \mathrm{M}$. Foi feita outra centrifugação a $13.000 \mathrm{rpm}$ por $5 \mathrm{~min}$. O sobrenadante foi desprezado e o precipitado foi lavado duas vezes com etanol $70 \%$ e misturado com $100 \mu \mathrm{L}$ de tampão de extração. A concentração de DNA de cada amostra foi determinada em um espectrofotômetro, com base na absorbância a $260 \mathrm{~nm}$. Para cada acesso, foi feito um "bulk", misturando-se $2 \mu \mathrm{g}$ de DNA de cada um dos 10 indivíduos. Deste "bulk" final, $1 \mu \mathrm{L}$ ( $25 \mathrm{ng}$ de DNA) foi utilizado em cada PCR. Além das 25 ng de DNA ( $1 \mu \mathrm{L})$, cada reação PCR continha $3 \mu \mathrm{L}$ de tampão (Tris-HCl $10 \mathrm{mM} \mathrm{pH} \mathrm{8,3),} \mathrm{0,39} \mu \mathrm{L}$ de $\mathrm{MgCl}_{2}(50 \mathrm{mM}), 0,26 \mu \mathrm{L}$ de dNTP $10 \mathrm{mM}, 3 \mu \mathrm{L}(5 \mathrm{ng} / \mu \mathrm{L})$ do iniciador, 0,20 $\mu \mathrm{L}$ (1U) de Taq DNA polimerase e $2,15 \mathrm{~mL}$ de água destilada, totalizando $10 \mu \mathrm{L}$. Foi feito um teste preliminar de primers (iniciadores) da empresa Operon Technologies (Alameda, CA, USA) dos quais nove foram selecionados (Tabela 2). As reações foram realizadas em um termociclador PTC-100 (MJ Research Inc., EUA), com 39 ciclos (1 min a $92^{\circ} \mathrm{C}, 1 \mathrm{~min}$ a $37^{\circ} \mathrm{C}$ e 2 min a $72^{\circ} \mathrm{C}$ ) mais 5 minutos a $72^{\circ} \mathrm{C}$ para finalizar a reação. Os produtos amplificados foram separados por eletroforese em géis de agarose a 1,5\% em tampão TBE (Tris Borato $90 \mathrm{mM}$, EDTA $1 \mathrm{mM}$ ), géis corados com brometo de etídio e fotografados sob luz UV. Foi utilizado um padrão de peso molecular de $100 \mathrm{pb}$ (Gibco RBL) para se estimar o tamanho das bandas amplificadas.

Os marcadores isoenzimáticos e RAPD obtidos consistentemente foram codificados como 1 ou 0 , para presença e ausência da marca, respectivamente, obtendo-se uma matriz binária a partir da qual foram calculados os coeficientes de similaridade de Jaccard entre os acessos. Esses coeficientes foram utilizados para a construção de dendrogramas adotando-se como critério de agrupamento o método do UPGMA (Unweighted Pair-Group Method of Arithmetic Averages). Marcadores isoenzimáticos e RAPD foram analisados separadamente, com o auxílio do software NTSYS PC (Rohlf, 2001).

Estimativas de distâncias geográficas entre locais de coleta de 13 acessos foram calculadas de acordo com Steiner \& Garcia de Los Santos (2001), utilizando-se as informações de latitude e longitude disponíveis (Tabela 1).

\section{Resultados e Discussão}

Nos nove acessos analisados com base em marcadores isoenzimáticos, foram detectadas 32 bandas anódicas para peroxidase e 13 bandas anódicas para $\beta$ esterase, todas polimórficas. Rivas (2001), analisando progênies de uma população natural de $B$. auleticus do Uruguai, encontrou 10 bandas de peroxidase e três de esterase em folhas, e cinco e quatro, respectivamente, em coleóptiles. Para peroxidase, uma única banda era exclusiva do acesso 06 e, para esterase, duas bandas eram exclusivas do acesso 03. A matriz de similaridade entre os acessos, com base nos marcadores isoenzimáticos (Tabela 3 ), assim como a análise de agrupamento dos acessos (Figura 1), mostrou alta variabilidade intrapopulacional. O coeficiente de similaridade médio entre todos os acessos foi de 0,27 , sendo os maiores $(0,50)$ obtidos entre os acessos 4 e 6,7 e 9 e 14 e 16 e o menor $(0,00)$ entre os acessos 4 e 13 . Dalagnol 
Tabela 3 - Matriz de similaridade (coeficiente de Jaccard) entre nove acessos de Bromus auleticus com base em marcadores isoenzimáticos peroxidase e $\beta$-esterase

Table 3 - Similarity matrix (Jaccard coefficient) among nine accessions of Bromus auleticus based on peroxidase and $\beta$-esterase isozyme markers

\begin{tabular}{|c|c|c|c|c|c|c|c|c|c|}
\hline $\begin{array}{l}\text { Acesso } \\
\text { Accession }\end{array}$ & 03 & 04 & 06 & 07 & 09 & 13 & 14 & 15 & 16 \\
\hline 03 & - & & & & & & & & \\
\hline 04 & 0,09 & - & & & & & & & \\
\hline 06 & 0,11 & 0,50 & - & & & & & & \\
\hline 07 & 0,29 & 0,29 & 0,43 & - & & & & & \\
\hline 09 & 0,25 & 0,15 & 0,24 & 0,50 & - & & & & \\
\hline 13 & 0,26 & 0,00 & 0,07 & 0,29 & 0,25 & - & & & \\
\hline 14 & 0,21 & 0,17 & 0,31 & 0,26 & 0,31 & 0,28 & - & & \\
\hline 15 & 0,08 & 0,23 & 0,32 & 0,20 & 0,22 & 0,13 & 0,38 & - & \\
\hline 16 & 0,26 & 0,26 & 0,25 & 0,37 & 0,43 & 0,26 & 0,50 & 0,16 & - \\
\hline
\end{tabular}

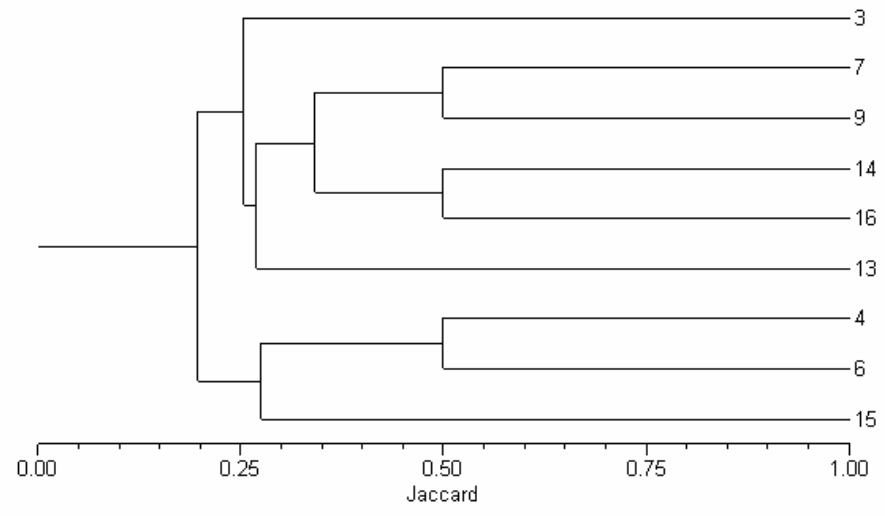

Figura 1 - Análise de agrupamento de nove acessos de Bromus auleticus por meio da matriz de similaridade calculada utilizando-se os marcadores isoenzimáticos. O método do UPGMA foi utilizado como critério de agrupamento.

Figure 1 - Cluster analysis of nine accession of Bromus auleticus based on the similarity matrix from isozymes. UPGMA method was used for clustering.

(2000) analisou nove sistemas enzimáticos em nove acessos do Uruguai e verificou índices de similaridade mais altos que os encontrados neste trabalho, variando de 0,577 a 0,944 , o que pode ser explicado pela origem semelhante dos acessos analisados, além do possível efeito homogeneizador de seleção, uma vez que esses eram mantidos há vários anos em uma estação experimental.

A análise da variabilidade genética dentro de cada acesso por meio dos marcadores isoenzimáticos não revelou a presença de indivíduos idênticos. Os coeficientes médios de similaridade entre os indivíduos de cada acesso foram em geral menores, média geral 0,18 (Tabela 4) que aqueles entre os acessos, média geral 0,27 , para ambos os sistemas enzimáticos em conjunto (Tabela 3). Isoenzimas foram utilizadas com sucesso na determinação da diversidade genética e das relações filogenéticas em outras espécies de Bromus, como aquelas das secções Genea (Oja \& Jaaska, 1996; 1998) e Bromus (Oja, 1998). As duas espécies diplóides autógamas (B. tectorum e $B$. sterilis) apresentaram maior variabilidade interespecífica que intraespecífica e acessos de diferentes origens geográficas variaram na quantidade de polimorfismo (Oja, 1999).

Não houve correlação entre os grupos de similaridade genética (Figura 1) com as distâncias geográficas (Tabela 5), ou seja, acessos com menores distâncias geográficas não ficaram agrupados e vice-versa.

Quanto aos 12 acessos analisados por meio dos marcadores RAPD, foram observados um total de 36 fragmentos, variando de 1.070 a 1.760 pares de bases, com média de 4,5 fragmentos por iniciador. Dalagnol (2000) encontrou 136 bandas para 37 iniciadores entre os 11 acessos analisados de B. auleticus do Uruguai (média de 2,7 fragmentos por iniciador). Esse resultado, juntamente com a alta similaridade encontrada no material analisado pelo autor com base em padrões de isoenzimas, apóia a hipótese de que o material já havia sofrido algum tipo de estreitamento da variabilidade genética, em razão da seleção.

Com base na análise realizada pelo método de "bulk", reunindo o DNA dos dez indivíduos de cada acesso, bandas raras não foram detectadas, uma vez que, normalmente, quando é feito um "bulk", aqueles fragmentos com freqüência inferiores entre 10 a $14 \%$ não são amplificados (Michelmore et al., 1991; Loarce et al., 1996). Entretanto, essa desvantagem do método 
Tabela 4 - Coeficiente médio de similaridade (Jaccard) entre cinco indivíduos dentro de nove acessos de Bromus auleticus calculados por meio de marcadores isoenzimáticos peroxidase e $\beta$-esterase

Table 4 - Mean similarity coefficients (Jaccard) among five individuals within nine Bromus auleticus accessions based on peroxidase and $\beta$-esterase isozyme markers

Sistema enzimático

Enzymatic system Accession

Acesso

\begin{tabular}{lccccccccc}
\cline { 2 - 9 } & 03 & 04 & 06 & 07 & 09 & 13 & 14 & 15 & 16 \\
\hline Peroxidase & 0,20 & 0,38 & 0,03 & 0,11 & 0,28 & 0,11 & 0,14 & 0,12 & 0,08 \\
Esterase & 0,17 & 0,38 & 0,20 & 0,18 & 0,24 & 0,40 & 0,32 & 0,06 & 0,38 \\
Peroxidase/Esterase & 0,17 & 0,36 & 0,08 & 0,14 & 0,23 & 0,20 & 0,20 & 0,12 & 0,16 \\
\hline
\end{tabular}

Tabela 5 - Distâncias geográficas entre os locais de coleta de 13 acessos de Bromus auleticus Table 5 - Geographical distances among places of collection of 13 Bromus auleticus accessions

\begin{tabular}{|c|c|c|c|c|c|c|c|c|c|c|c|c|c|}
\hline $\begin{array}{l}\text { Acesso } \\
\text { Accession }\end{array}$ & 01 & 02 & 03 & 04 & 05 & 06 & 07 & 08 & 09 & 10 & 11 & 12 & 13 \\
\hline 01 & - & & & & & & & & & & & & \\
\hline 02 & 211,62 & - & & & & & & & & & & & \\
\hline 03 & 257,36 & 257,50 & - & & & & & & & & & & \\
\hline 04 & 265,49 & 265,66 & 111,55 & - & & & & & & & & & \\
\hline 05 & 257,04 & 257,17 & 106,72 & 110,56 & - & & & & & & & & \\
\hline 06 & 137,74 & 138,11 & 24,45 & 28,33 & 23,38 & - & & & & & & & \\
\hline 07 & 42,88 & 42,17 & 15,63 & 9,34 & 17,32 & 174,96 & - & & & & & & \\
\hline 08 & 38,38 & 37,67 & 23,04 & 16,81 & 24,77 & 183,36 & 131,15 & - & & & & & \\
\hline 09 & 218,78 & 217,79 & 281,44 & 290,08 & 281,10 & 155,98 & 47,72 & 43,21 & - & & & & \\
\hline 10 & 225,85 & 225,88 & 207,58 & 214,25 & 207,32 & 110,61 & 44,10 & 39,17 & 242,21 & - & & & \\
\hline 11 & 217,82 & 216,93 & 277,09 & 285,61 & 276,76 & 153,50 & 47,42 & 42,92 & 221,70 & 239,05 & - & & \\
\hline 12 & 257,32 & 257,44 & 105,76 & 109,59 & 104,76 & 22,28 & 19,08 & 26,58 & 281,40 & 207,55 & 277,07 & - & \\
\hline 13 & 4,70 & 5,39 & 97,31 & 91,38 & 99,45 & 272,74 & 174,62 & 179,13 & 0,10 & 8,20 & 0,11 & 101,86 & - \\
\hline
\end{tabular}

de "bulk" em não estimar a variabilidade entre os indivíduos de uma população é superada pela vantagem da rápida verificação de diferenças entre populações, o que é especialmente importante para programas de melhoramento genético. Mesmo com o "bulk", os padrões de RAPD das 12 populações de cevadilha analisadas demonstraram alta variabilidade genética interpopulacional (Tabela 6; Figura 2). Os coeficientes de similaridade entre pares de acessos variaram de 0,15 a 0,71 e o coeficiente de similaridade médio entre todos os acessos foi de 0,41 .

Assim como para os marcadores isoenzimáticos, não foi verificada correlação entre distâncias geográficas e coeficientes de similaridade calculados por meio dos marcadores RAPD. A distância geográfica por si só pode não ser um padrão confiável para se estimar a similaridade genética, especialmente em uma área relativamente pequena como a do Rio Grande do Sul. Além disso, fatores ambientais, como composição e umidade do solo, precipitação média e quantidade de radiação poderiam ser muito mais

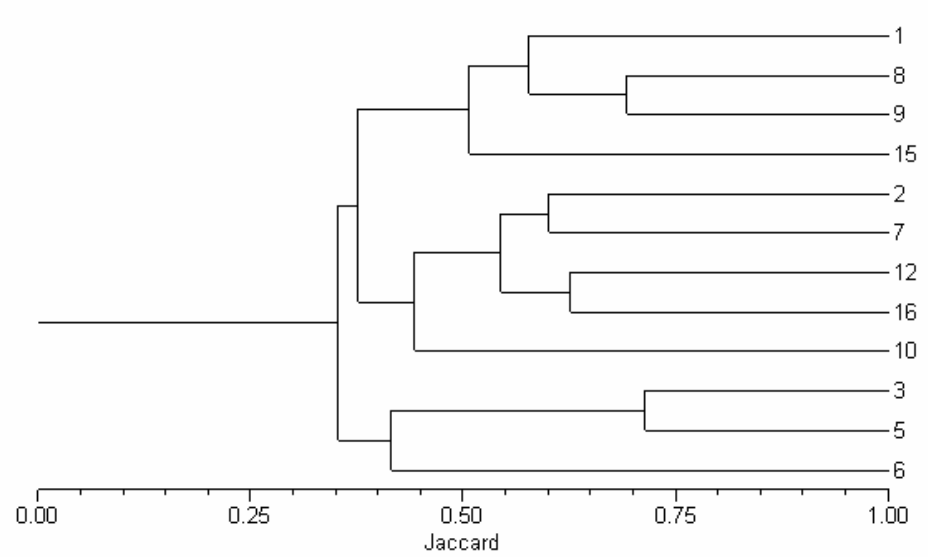

Figura 2 - Análise de agrupamento de 12 acessos de Bromus auleticus com base na matriz de similaridade calculada utilizando-se 36 marcadores RAPD. O método do UPGMA foi utilizado como critério de agrupamento.

Figure 2 - Cluster analysis of 12 accession of Bromus auleticus based on the similarity matrix from 36 RAPD markers. UPGMA method was used for clustering. 
Tabela 6 - Matriz de similaridade (coeficiente de Jaccard) entre 12 acessos de Bromus auleticus com base em 36 marcadores RAPD

Table 6 - Similarity matrix (Jaccard coefficient) among 12 Bromus auleticus accessions based on 36 RAPD markers

\begin{tabular}{|c|c|c|c|c|c|c|c|c|c|c|c|c|}
\hline $\begin{array}{l}\text { Acesso } \\
\text { Accession }\end{array}$ & 01 & 02 & 03 & 05 & 06 & 07 & 08 & 09 & 10 & 12 & 15 & 16 \\
\hline 01 & - & & & & & & & & & & & \\
\hline 02 & 0,56 & - & & & & & & & & & & \\
\hline 03 & 0,43 & 0,50 & - & & & & & & & & & \\
\hline 05 & 0,44 & 0,38 & 0,71 & - & & & & & & & & \\
\hline 06 & 0,38 & 0,38 & 0,40 & 0,43 & - & & & & & & & \\
\hline 07 & 0,15 & 0,60 & 0,27 & 0,31 & 0,31 & - & & & & & & \\
\hline 08 & 0,60 & 0,46 & 0,30 & 0,37 & 0,22 & 0,41 & - & & & & & \\
\hline 09 & 0,56 & 0,64 & 0,50 & 0,38 & 0,29 & 0,33 & 0,69 & - & & & & \\
\hline 10 & 0,27 & 0,55 & 0,33 & 0,47 & 0,40 & 0,35 & 0,27 & 0,46 & - & & & \\
\hline 12 & 0,17 & 0,44 & 0,29 & 0,44 & 0,22 & 0,57 & 0,33 & 0,33 & 0,56 & - & & \\
\hline 15 & 0,38 & 0,43 & 0,36 & 0,50 & 0,33 & 0,50 & 0,60 & 0,53 & 0,45 & 0,50 & - & \\
\hline 16 & 0,15 & 0,55 & 0,22 & 0,24 & 0,21 & 0,62 & 0,32 & 0,42 & 0,31 & 0,63 & 0,37 & - \\
\hline
\end{tabular}

Tabela 7 - Coeficientes de similaridade de Jaccard entre seis acessos de Bromus auleticus com base em marcadores isoenzimáticos e em marcadores RAPD (negrito)

Table 7 - Similarity coefficients (Jaccars) among six Bromus auleticus accessions based on isozymes and RAPD markers (bold)

\begin{tabular}{|c|c|c|c|c|c|c|c|c|c|c|c|c|}
\hline $\begin{array}{l}\text { Acesso } \\
\text { Accession }\end{array}$ & \multicolumn{2}{|c|}{03} & \multicolumn{2}{|c|}{06} & \multicolumn{2}{|c|}{07} & \multicolumn{2}{|c|}{09} & \multicolumn{2}{|c|}{15} & \multicolumn{2}{|c|}{16} \\
\hline 03 & - & - & & & & & & & & & & \\
\hline 06 & 0,11 & $\mathbf{0 , 4 0}$ & - & - & & & & & & & & \\
\hline 07 & 0,29 & $\mathbf{0 , 2 7}$ & 0,43 & $\mathbf{0 , 3 1}$ & - & - & & & & & & \\
\hline 09 & 0,25 & $\mathbf{0 , 5 0}$ & 0,24 & 0,29 & 0,50 & $\mathbf{0 , 3 3}$ & - & - & & & & \\
\hline 15 & 0,08 & 0,36 & 0,32 & $\mathbf{0 , 3 3}$ & 0,20 & $\mathbf{0 , 5 0}$ & 0,22 & $\mathbf{0 , 5 3}$ & - & - & & \\
\hline 16 & 0,26 & 0,22 & 0,25 & 0,21 & 0,37 & 0,62 & 0,43 & 0,42 & 0,16 & $\mathbf{0 , 3 7}$ & - & - \\
\hline
\end{tabular}

determinantes para a similaridade genética que a simples distância geográfica.

Os dados encontrados, tanto para isoenzimas como para RAPD, indicam alta variabilidade genética nas populações naturais analisadas de B. auleticus do Rio Grande do Sul, o que está de acordo com relatos prévios de variabilidades morfológica, fisiológica e agronômica (Oliveira \& Moraes, 1993; Soares, 1999). B. auleticus é uma espécie alógama (Rivas, 2001) e de polinização anemófila. Espécies alógamas são, por definição, muito mais variáveis que as autógamas. Por exemplo, a análise da variabilidade genética em 10 espécies de Lathyrus comprovou níveis de diversidade maiores para as espécies alógamas que para as autógamas (Bem Brahim et al., 2002). Em espécies alógamas, como Lolium perenne (Kölliker et al., 1999), Trifolium pratense (Campos-de-Quiroz \& Ortega-Klose, 2001) e algumas de Adesmia (Dias, 2002), as porcentagens de locos polimórficos de RAPD foram 64, 80 e 56\%, respectivamente. Entretanto, podem haver exceções, como na espécie autógama Lathyrus sativus, em que $50 \%$ dos fragmentos de RAPD eram polimórficos (Croft et al., 1999). Em algumas populações de espécies alógamas, pode ser encontrada variabilidade intrapopulacional maior que inter-populacional, como em Lolium perenne (Sweeney \& Dannenberger, 1994), Trifolium pratense (Kongkiatngam et al., 1995), Medicago sativa (Yu \& Pauls, 1993; Crochemore et al., 1996) e Ilex paraguariensis (Gauer \& CavalliMolina, 2000). Ferdinandez \& Coulman (2002) também detectaram variabilidade para RAPD e AFLP 
maior dentro das populações que entre as populações analisadas de $B$. inermis e B. riparius. Os resultados obtidos neste estudo para $B$. auleticus mostram maior variabilidade média dentro das populações que entre as populações, quando dois sistemas isoenzimáticos foram analisados, embora a amplitude de variação tenha sido maior na avaliação realizada entre os acessos (Tabela 3). Entretanto, esse resultado não foi claramente evidenciado pela análise com marcadores RAPD, em razão da utilização do método do "bulk". Para os seis acessos examinados pelas duas técnicas, os índices de similaridade foram em geral mais altos para RAPD que para isoenzimas (Tabela 7), sendo a correlação simples entre esses índices de 0,029. Essa baixa correlação pode ser explicada pelo uso de apenas dois sistemas enzimáticos. Os índices médios de similaridade entre esses seis acessos foram de 0,38 para RAPD e 0,27 para as isoenzimas, o que pode ser explicado pela codominância dos marcadores isoenzimáticos em relação à dominância dos marcadores RAPD. Dalagnol (2000) encontrou índices de similaridades mais altos para isoenzimas $(0,982)$ que para $\operatorname{RAPD}(0,816)$ entre os acessos de $B$. auleticus por ele analisados. Esta diferença entre os dados de Dalagnol (2000) e os deste trabalho pode ser explicada pelo diferente número de sistemas enzimáticos e iniciadores utilizados e também pelas diferenças genéticas entre os grupos de populações analisadas.

\section{Conclusões}

Os resultados mostram a variabilidade genética inter e intra-populacional de Bromus auleticus coletado no Rio Grande do Sul, a qual é importante para subsidiar ações futuras de programas de melhoramento genético e de programas de conservação e o uso de recursos genéticos. Os resultados comprovam também a utilidade de marcadores isoenzimáticos e RAPD na caracterização da variabilidade genética.

\section{Agradecimento}

Ao Conselho Nacional de Desenvolvimento Científico e Tecnológico (CNPq), pela bolsa de Mestrado para a primeira autora. À Financiadora de Estudos e Projetos (FINEP), ao CNPq e à Fundação de Amparo à Pesquisa do Estado do Rio Grande do Sul (FAPERGS), pelo auxílio financeiro.

\section{Literatura Citada}

ALFENAS, A.C.; DUSI, A.; ZERBINI JR., F.M. et al. Eletroforese de isoenzimas e proteínas afins: fundamentos e aplicações em plantas e microorganismos. Viçosa, MG: Universidade Federal de Viçosa, 1998. 574p.

ARAÚJO, A.A. Principais gramíneas do Rio Grande do Sul. Porto Alegre: Sulina, 1971. 255p.

BEM BRAHIM, N.; SALHI, A.; CHTOUROU, N. et al. Isozymic polymorphism and phylogeny of 10 Lathyrus species. Genetic Resources and Crop Evolution, v.49, p.427-436, 2002.

CAMPOS-DE-QUIROZ, H.; ORTEGA-KLOSE, F. Genetic variability among elite red clover (Trifolium pratense L.) parents used in Chile as revealed by RAPD markers. Euphytica, v.122, p.61-67, 2001.

CARLSON, I.T.; NEWELL, L.C. Smooth bromegrass. In: HEATH, M.E.; BARNES, R.F.; METCALFE, D.S. (Eds) Forages. 4.ed. Ames: Iowa State University Press, 1985. p.198-206.

CROCHEMORE, M.L.; HUYGHE, C.; KERLAN, M.C. et al. Partitioning and distribution of RAPD variation in a set of populations of the Medicago sativa complex. Agronomie, v.16, p.421-432, 1996.

CROFT, A.M.; PANG, E.C.K.; TAYLOR, P.W.J. Molecular analysis of Lathyrus sativus L. (grasspea) and related Lathyrus species. Euphytica, v.107, p.167-176, 1999.

DALAGNOL, G.L. Diversidade genética de 11 acessos e progênies e performance agronômica de dois sintéticos de Bromus auleticus Trinius. Florianópolis: Universidade Federal de Santa Catarina, 2000. 102p. Dissertação (Mestrado em Recursos Genéticos Vegetais) - Universidade Federal de Santa Catarina, 2000.

DIAS, P.M.B. Caracterização de espécies brasileiras de Adesmia DC por RAPD. Porto Alegre: Universidade Federal do Rio Grande do Sul, 2002. 130p. Dissertação (Mestrado em Zootecnia, Plantas Forrageiras) - Universidade Federal do Rio Grande do Sul, 2002.

FERDINANDEZ, Y.S.N.; COULMAN, B.E. Evaluating genetic variation and relationships among two bromegrass species and their hybrid using RAPD and AFLP markers. Euphytica, v.125, p.281-291, 2002.

GAUER, L.; CAVALLI-MOLINA, S. Genetic variation in natural populations of maté (Ilex paraguariensis A. St.Hil., Aquifoliaceae) using RAPD markers. Heredity, v.84, p.647-656, 2000.

GONZALEZ, A.C.; SCHIFINO-WITTMANN, M.T. Isoenzymatic characterization of some Lathyrus L. and Vicia L. species (Leguminosae) occurring in Rio Grande do Sul (Southern Brazil). Revista Brasileira de Genética, v.19, p.283-288, 1996.

KLAAS, M. Applications and impact of molecular markers on evolutionary and diversity studies in Allium. Plant Breeding, v.117, p.297-308, 1998.

KÖLLIKER, R.; STADELMANN, F.J.; REIDY, B. et al. Genetic variability of forage grass cultivars: a comparison of Festuca pratensis Huds., Lolium perenne L., and Dactylis glomerata L. Euphytica, v.106, p.261-270, 1999.

KONGKIATNGAM, P.; WATERWAY, M.J.; FORTIN, M.F. et al. Genetic variation within and between two cultivars of red clover (Trifolium pratense L.): comparisons of morphological, isozyme, and RAPD markers. Euphytica, v.84, p.237-246, 1995. 
LANGE, O.; SCHIFINO-WITTMANN, M.T. Isozyme variation in wild and cultivated species of the genus Trifolium L. (Leguminosae). Annals of Botany, v.86, p.339-345, 2000.

LI, Y.G.; DEWALD, C.L.; SIMS, P.L. Genetic relationships within Tripsacum as detected by RAPD variation. Annals of Botany, v.84, p.695-702, 1999.

LOARCE, Y.; GALLEGO, R.; FERRER, E. A comparative analysis of genetic relationships; between rye cultivars using RFLP and RAPD markers. Euphytica, v.88, p.107$115,1996$.

LONGHI, H.M. O gênero Bromus L. (Gramineae) no Rio Grande do Sul. In: CONGRESSO NACIONAL DE BOTÂNICA, 36 ., 1977, Rio de Janeiro. Proceedings... Rio de Janeiro: Academia Brasileira de Ciências, 1977. p.333-342.

MABBERLEY, D.J. The plant-book. Cambridge: Cambridge University Press, 1997. 858p.

MARTINELLO, G.; SCHIFINO-WITTMANN, M.T. Chromosomes of Bromus auleticus Trin. ex Nees (Poaceae). Genetics and Molecular Biology, v.26, p.369-371, 2003.

MICHELMORE, R.W.; PARANM, I.; KESSELI, R.V. Identification of markers linked to disease resistance genes by bulk segregant analysis: a rapid method to detect markers in specific genomic regions using segregating populations. Proceedings of the National Academy of Sciences of the USA, v.88, p.9828-2832, 1991.

OJA, T. Isoenzyme diversity and phylogenetic affinities in the section Bromus of the grass genus Bromus (Poaceae). Biochemical Systematics and Evolution, v.26, p.403-413, 1998.

OJA, T. Allozyme diversity and interspecific differentiation of the two diploid bromegrass species, Bromus tectorum L. and B. sterilis L. (Poaceae). Plant Biology, v.1, p.679-686, 1999.

OJA, T.; JAASKA, V. Isoenzyme data on the genetic divergence and allopolyploidy in the section Genea of the grass genus Bromus (Poaceae). Hereditas, v.125, p.249-255, 1996.

OJA, T.; JAASKA, V. Allozyme diversity and phylogenetic relationships among diploid annual bromes (Bromus, Poaceae). Annales Botanici Fennici, v.35. p.123-130. 1998.
OLIVEIRA, J.C.P.; MORAES, C.O. Distribuição da produção e qualidade de forragem de Bromus auleticus Trinius. Pesquisa Agropecuária Brasileira, v.28, p.391-398, 1993.

RIVAS, M. Sistema reproductivo y estructura genética de poblaciones de Bromus auleticus Trinius ex-Nees (Poaceae). Estudio mediante isoenzimas. Agrociencia, v.5, p.32-40, 2001.

ROHLF, J. NTSYS-pc. Numerical taxonomy and multivariate analysis system. Version. 2.1. New York: Exeter, 2001. Software.

SOARES, G.C. Caracterização agronômica e melhoramento genético de uma população de cevadilha vacariana (Bromus auleticus Trinius). Porto Alegre:Universidade Federal do Rio Grande do Sul, 1999. 123p. Dissertação(Mestrado em Zootecnia, opção Plantas Forrageiras) - Universidade Federal do Rio Grande do Sul, 1999.

SOLTIS, D.E.; SOLTIS, P.S. Isoenzymes in plant biology. London: Chapman \& Hall, 1989. 268p.

STEINER, J.J.; GARCIA DE LOS SANTOS, G. Adaptative ecology of Lotus corniculatus L. genotypes: I. Plant morphology and RAPD marker characterizations. Crop Science, v.41, p.552-563, 2001.

SWEENEY, P.M.; DANNEBERGER, K.T. Random amplified polymorphic DNA in perennial ryegrass: a comparison of bulk samples vs. individuals. Hortscience, v.29, p.624-626, 1994.

THOMSON, D.; HENRY, R. Single-step procol for prepparation of plant tissue for analysis by PCR. Biotechniques, v.19, p.552-563, 1995 .

YU, K.; PAULS, K.P. Rapid estimation of genetic relatedness among heterogeneous populations of alfalfa by random amplification of bulked DNA samples. Theoretical and Applied Genetics, v.86, p.788-794, 1993.

Recebido em: 14/10/04

Aceito em: 14/06/05 